\title{
DETERMINATION OF SLEEP PATTERN AND IMPACT OF SLEEP DEPRIVATION IN ADULTS
}

\author{
Prakash Kumar Kaushik \\ Bilaspur c.g. India
}

\begin{abstract}
The main aim of this paper is to analyze the impact of sleep deprivation in adults. Today prolonged wakefulness is widespread phenomenon and spreading due to attitude in society that sleep is highly compressible, but sleep deprivation induce adverse changes in cognitive performance and also lead to aggressiveness, insomnia, laziness, drowsy feeling and lack of concentration. Thus sleep deprivation is a public health hazard.
\end{abstract}

Keyword- Sleep pattern, Sleep deprivation, Public health, Cognitive performance.

\section{INTRODUCTION}

Sleep is a state of body and mind which typically recurs for several hours every night. In which nervous system is inactive and consciousness practically suspended. In normal adults there are two main stages of sleep that alternate at about 90 minute of interval. Rapid eye movement (REM) sleep can be described as a period when the brain is active and the body is paralyzed (except for eye movement, Middle ear ossicle and Respiration). In non-rapid eye movement (N REM) sleep, the brain is less active but body can move. Body's sleep-wake cycle is under circadian rhythm.

Sleep affect physical growth, behavior, emotion, cognitive function, learning and attention,

Productivity. Apart from physiology psychological, environmental and gut micro biome factor, socioeconomic factor also play major role in determining the sleep pattern of a person. Lack of Adequate sleep is is a possible risk factor for multiple organ failure and various disorders. Sleep is increasingly recognized as important to public health with sleep insuffiency linked to motor vehicle crashes, industrial disasters medical and other occupational errors. Unintentionally falling asleep (insomnia), having difficulty in performing a cognitive task's. because of sleep deprivation all may contribute to hazardous outcomes. Person suffering with sleep deprivation are also more likely to suffer from chronic diseases such as hypertension, diabetes, obesity, increased mortality risk, reduced quality of life and productivity. Most of studies regarding-sleep habits in adolescent are from west, however a few Asian studies (1-4) are available. Sleep pattern is linked with the academic performance starting in adolescent In recognition of the importance of sleep to the nation's health, CDC. surveillance of sleep related behavior has increased in recent years. Additionally the institute of medicine encouraged collaboration between CDC and the national center on sleep disorder research to support development one expansion of adequate surveillance of the us population sleep pattern and associated outcomes. Two new reports on the prevalence of unhealthy sleep behavior and self-reported sleep related difficulties among us. adults provide furthered evidence that insufficient sleep is an important public health concern. Thus this study is proposed to determine the impact of sleep deprivation on the health and academics of adult.

\section{OBJECTIVE}

1. To determine the sleep pattern among students.

2. To access the effect of sleep deprivation on the health and academics of adult's.

\section{METHOD}

A determinative study was carried out by prakash kaushik during unlock 1.0(covid-19). 100 undergraduate students were taken for convenient sampling technique. Interview was taken from all students for study till the sample size is achieved. They were explained about purpose of study and the questions were explained to them and asked about to answer through social media app whatsapp, facebook, instagram. It was a self administered semi-structured questionnaire given to them. After data collection it was entered in excel sheet and analyzed descriptive statistics was applied and results were represented in the form of figure, graph, table, chart, wherever necessary. 


\section{RESULTS}

It observed from the study that the mean age group of the undergraduates who participated in the study was $80 \pm$. All are boys .Most of them(60\%) stay in hostel and few (40\%) are day scholars.32\% of them had abnormal sleep pattern is the one where circadian rhythm is disturbed and they sleep for less than $6 \mathrm{Hrs} /$ day. It is observed that among sleep deprived adult students 21 of them were affected in their academics where they mentioned during exams they feel sleepy and not able to concentrate on class and 11 of them are affected in their health like change in mental health behavior.

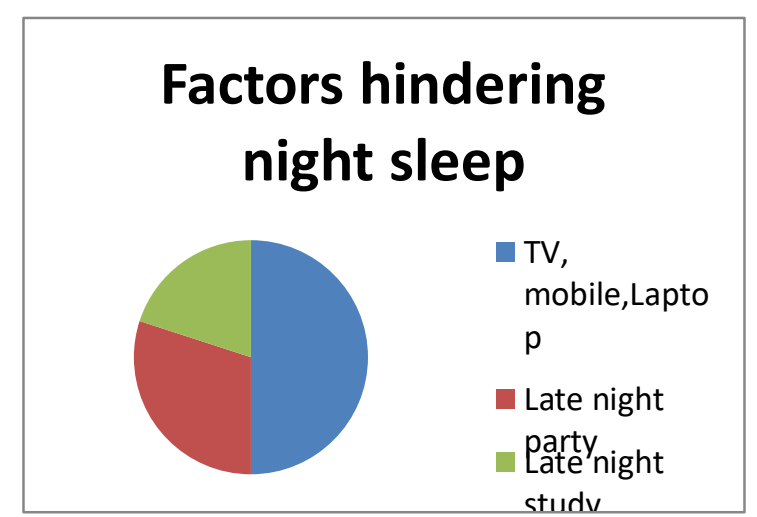

Fig- Socio-demographic detail

\begin{tabular}{|l|l|l|}
\hline Adult(Boys) & Normal sleep & Deprived \\
\hline 100 & 68 & 32 \\
\hline
\end{tabular}

\begin{tabular}{|l|l|l|}
\hline Adult(Boys) & Hostel & localities \\
\hline 100 & 60 & 40 \\
\hline
\end{tabular}

\section{Fig-Sleep pattern distribution}

\section{DISCUSSION}

From the present study, it is seen that normal sleep pattern among medical students is seen to a lesser extent and abnormal sleep pattern is rising in trend, which is alarmist and has to gain special focus on the same. Many studies are done about the sleep pattern among medical residents and school children all have shown significant relation between sleep deprivation and its effect on health.9 A study done by Rosen et al on the prevalence of chronic sleep deprivation, depression burnout, and empathy increased from baseline to year end. Specifically, the prevalence of "high" scores changed for chronic sleep deprivation (9\% to $43 \%$, $\mathrm{p}=0.0001)$. The prevalence of moderate depression increased from $4.3 \%$ to $29.8 \%$ ( $\mathrm{p}=0.0002$ ). There was an association between becoming chronically sleep deprived and becoming depressed $(\mathrm{OR}=7$, $\mathrm{p}=0.014) .10$

In our study we found that $34.86 \%$ of sleep deprived students went for depression followed by agitation which affected their daily routine at a significant level.

A study done by Baviskar et al to describe sleep habits and sleep problems in a population of undergraduates, interns and postgraduate students of Pravara Institute of Medical Sciences (Deemed University), Loni, Maharashtra, India showed that out of 150 medical students, 26/150 (17.3\%) students had abnormal levels of daytime sleepiness while 20/150 (13.3\%) were border line. Sleep quality in females was better than the male.11 It is observed from the study that out of 200 medical students, the mean age group who participated in the study was $20.65 \pm 0.65 \mathrm{SD}$.

The cross-sectional study done by Aesha et al in King Khalid Medical College, Saudi Arabia, enrolled 318 medical students during OctoberNovember, 2015 by Convenient sampling showed that the overall mean sleep quality score was 6.79 with a standard deviation of 3.06. Poor sleep quality was reported by $74.2 \%$ students. Poor sleep was predicted by sleep behaviors such as going to sleep after midnight $(\mathrm{AOR}=2.18,95 \%$ CI: 1.20 , 3.94) and sleep duration of less than seven hours (AOR=7.49, 95\% CI: 4.24, 13.22). 12

Sleep quality and its psychological correlates among university students in Ethiopia: a crosssectional study by Lemma et al on the prevalence of poor sleep quality (total PSQI score>5) was $55.8 \%(1,424)$. Female students (adjusted odds ratio (AOR) 1.23; 95\% CI: 1.00, 1.57), second year (AOR 2.91; 95\% CI: 2.1, 4.02) and third year students (AOR 2.25; 95\% CI 1.62, 3.12) had statistically significant higher odds of poor sleep quality. Perceived stress level and symptoms of depression and anxiety were strongly associated with sleep quality.13

The interaction between sleep quality and academic performance by Ahrberg at al showed that academic performance correlated with stress and sleep quality pre-exam $(\mathrm{r}=0.276, \mathrm{p}<0.001$ and $\mathrm{r}=0.158, \mathrm{p}<0.03,59 \%$ of all participants exhibited clinically relevant sleep disturbances (PSQI>5) during exam preparation compared to $29 \%$ during the semester and $8 \%$ post-exam.14 It is observed from our study that among sleep deprived medical students, $61.9 \%$ of them were affected in their academics and $38.09 \%$ of them are affected in their health like change in mental health behaviors'. Similar study done on sleep quality among dental students and its association with academic performance-a cross-sectional study by Eagar et al among 1160 students from clinical and non-clinical levels to measure the sleep-related variables and academic performance The response rate was $62 \%$. 


\section{International Journal of Engineering Applied Sciences and Technology, 2020 \\ Vol. 5, Issue 4, ISSN No. 2455-2143, Pages 237-239 \\ Published Online August 2020 in IJEAST (http://www.ijeast.com)}

Sixty five percent of the students described their sleep as good or very good, whereas $35 \%$ described their sleep as bad or very bad. The mean number of hours of sleep per night for all students was $5.85 \pm 1.853$ hours. Sleep is one of the components of adolescent health. Adherence to electronic gadgets/late night browsing should be avoided. Sleep deprivation had a significant impact on health and academics. Sleep deprivation use to hinder their concentrating ability, failure to recollect answers and day time sleepiness in class. Sleep deprivation also affects mental condition and alter their behavior like depression, agitation, lethargy. Health education about sleep hygiene should be given among adolescents. It has to gain importance in the minds of students at a very early stage so as to prevent problems due to sleep deprivation.

\section{CONCLUSION}

In the present study the sleep habits of 32 adults are not conducive to health. Sleep disturbances are an important issue among graduation students. Sleep patterns are affected by age, gender, living condition despite numerous publication regarding the subject student tend to ignore sleep disorder and their consequences. Proper counseling proper planning and support should be provided to students suffering from sleep disorders and it may be related with high prevalence of addiction in male adults. Study show daytime sleepiness may result in mood disturbances and increased vulnerability to substance use.

\section{AKNOWLEDGEMENT}

First and foremost, Praises and thanks to GOD, The Almighty for his showers of blessing throughout my research work to complete the research successfully.

I would like to express my deep and sincere gratitude to all students and my friends who participated in study. I am extremely grateful to my parents for their love, Prayers, caring and sacrifices for educating and preparing me for my future.

\section{REFERENCE}

1. Giri pa et al.(2013).Study Of Sleep Problems Among Medical students of Pravara Institute of Medical Sciences Loni, Western Maharashtra, India.(DOI.10.4103/2141-9248.109488).

2. Sadeh et al.(2000).Sleep pattern and Sleep Disruption in School-Age Children's.(DOI.10.1037//0012-1649.36.3.291).
3. Philbert I et al.(2005).Sleep loss and Performance in Residents and Non-physicians: A Meta-Analytic

examination.(DOI.10.1093/sleep/28.11.1392).

4. Pilcher J et al. (1998). The Relationship Between Sleep and Measures of Health and well Being in College Students: A Repeated Measures Approach. (DOI.10.1080/089642.89809596373).

5. Schoenborn C et al.(2010). Health Behaviors of Adults(pg.1-132).

6. Mellinger G D et al.(1985).Insomnia and its Treatment Prevalence and Correlation.(DOI.10.1001/archpsyc. 1985.01790260 019002).

7. Tsui Y Y et al. (2009) A Study on The Sleep Pattern and Problems of University Business Students in Hong Kong. (DOI.10.1080/07448480903221418).

8. Ferrara M et al.(2001).How Much Sleep Do We Need.(DOI.10.1053/smrv.2000.0138).

9. Owensa JA et al.(2001)Physician Heal Thyself: Sleep, Fatigue , and Medical Education.(DOI.10.1093/sleep/24.5.493).

10. Howard SK et al. (2002). The Risk and Implication of Excessive Daytime Sleepiness in Resident Physician. (DOI.10.1097/00001888200210000-00015).

11. Veasey S et al.(2002).Sleep Loss and Fatigue in Residency Training A Reappraisal.(DOI.10.1001/Jama.288.9.1116).

12. Johns MW et al.(1991).A New Method for Measuring Daytime Sleepiness: The Epworth Sleepiness Scale.(Doi.10.1093/sleep/14.6.540).

13. Veldi M et al. (2005) Sleep Quality and More Common Sleep-Related Problems In Medical Students. (DOI.10.1016/J.sleep.2004.12.003).

14. Pilcher JJ et al.(1997).Sleep Quality Versus Sleep Quantity: Relationship Between Sleep and Measures of Health, Well-Being and sleepiness in College Students,(DOI.10.1016/s00223999(97)00004-4).

15. Wolfson et al. (1998).Sleep Schedules and Daytime Functioning in Adolescent.(pg.875-87). 